\title{
The Use of Technology Integration SAMR Model in Teaching English
}

\author{
Nyayu Yayu Suryani ${ }^{1}$, Heru Setiawan ${ }^{2}$, Masagus Sulaiman ${ }^{3}$ \\ ${ }^{1}$ STIK Siti Khadijah, Palembang \\ ${ }^{2}$ Universitas Yridinanti, Palembang \\ ${ }^{3}$ Universitas Muhammadiyah, Palembang
}

Received : 12 April 2019; Accepted : 28 May 2019

URL : http://ejournal.iainpalopo.ac.id/index.php/ideas

\begin{abstract}
Nowadays, information and communications technology (ICT) has been widely used either in schools or colleges. An understanding on the use of technology in language learning particularly in the class fascinated for both educators and learners. One of the language learning technologies is that SAMR, a model which is designed to help educators in embedding technology skills into the learning process in the classroom. In SAMR, 4 functions used to develop the applications, as in Substitution, Augmentation, Modification and Redefenition. This model helps educators provide an overview on the implementation of English language learning (i.e. reading, writing and listening). The simple SAMR model is certainly reminiscent of a model that was first in the realm of cognitive education. This model is parallel with the model of the taxonomy of bloom, a model that is very often used in cognitive learning. By applying SAMR Model, students can design learning technology effectively.
\end{abstract}

Keywords: Technology integration; SAMR model; Teaching English

\section{Introduction}

SAMR (Substitution, Augmentation, Modification and Redefinition) is a model triggered by Puentedura. Technology in schools, which is widely understood as the use of computers or learning aids using technology, often used only to the extent of knowledge from the learning itself. An understanding of the use of technology in classroom learning is very interesting because it will open the eyes of educators and learners. 
SAMR models are seen to be closer to integration technology itself. Mueller et al., (2013) state that the use of technology in learning, therefore in the SAMR model perspective, it is clearly a transformation in learning.

In line with the development of the use of technology, learning in the classroom has naturally shifted. In the past, computer laboratories have been used. A school that has a computer laboratory and even a language laboratory will be highly regarded as an advanced school. However, an interesting thing that should be observed, what is taught in the laboratory? Typing skill? Listening skills? data processing skills?, all of them are very supportive of daily work. The thing should be underlined here is that the word "support". Meanwhile, the current learning paradigm is not fragmented in certain learning disciplines, but interrelated. Interrelated between one learning and another is actually what happens in the real world.

\section{SAMR Model}

According to Puentedura (2013) SAMR model can be explained in Figure 1 below:

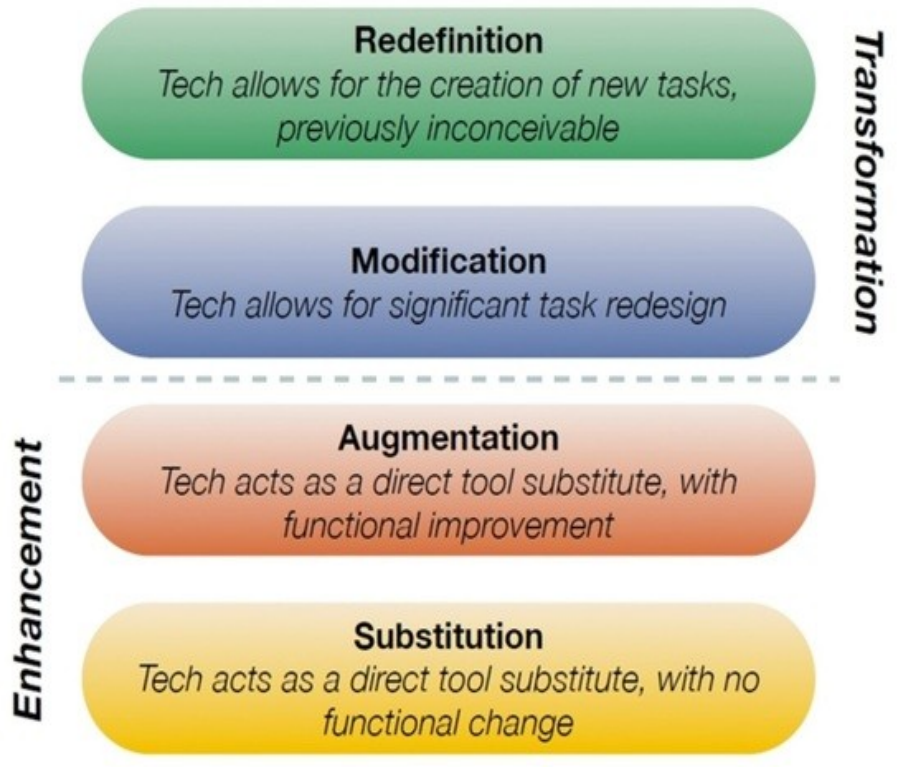

Figure 1: SAMR Model

The SAMR model consists of 4 levels, as follows:

1. Substitution, in this level, technology is used as a substitute for equipment used with no change in function. For example computers with word processing software such as MS Word function to replace the writing process that normally using a pen or a paper.

2. Augmentation, at this level, technology is used as a substitute for equipment used with the addition or improvement of functions. For example, 
using the same software by using available functions, such as functions to check spelling, even grammar.

3. Modification, in this level, technology makes it possible to change the way of better work. For example, by using the same computer, it enables to connect the internet. By using the Google docs application, it makes work group possible, and With Google docs, a partnerwho is from far away can even correct what has been done.

4. Redefinition, at this level, technology makes it possible to create ways of working that never even imagined before. For example, by using the internet and better software, it can make the writing process mucheasier by using multimedia applications.

\section{SAMR and Bloom's Taxonomy Model}

The original version that is well-known and widely recognized is the bloom taxonomy of educational goals (Bloom, et al., 1956), where three dimensions are defined (cognitive, affective and psychomotor), cognition is organized into six main categories, each of which is explained by a noun (knowledge, comprehension, application,analysis, synthesis, evaluation), was replaced and revised in 2001 by Anderson et al., including affective and psychomotor domains. They further state that the new cognitive version domain, which identically uses six categories classifies them in different order at the two highest levels and describes them in nouns. More reflecting forms of thinking that are more active and accurate (remember, understand, apply, analysis, evaluate, create).

The simple SAMR model is certainly reminiscent of a model that was first in the realm of cognitive education. This model is parallel with the model of the taxonomy of bloom, a model that is very often used in cognitive learning. The similarity of this method can be seen in the picture below:

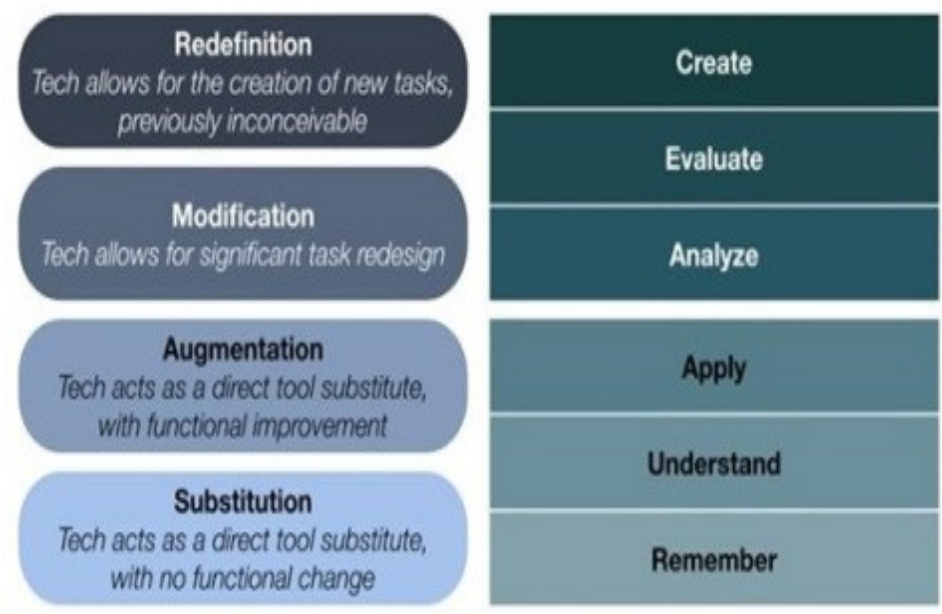


Nyayu Yayu Suryani

Heru Setiawan

Masagus Sulaiman:

The Use of Technology Integration Samr Model

In Teaching English

\section{The Application of SAMR Model}

In implementing the SAMR model, there are a number of things must be prepared such a lesson plan. This session focuses more on writing skills that can be taken in the SAMR model. Teachers and technology are integrated in identifying the steps in which the SAMR model will be used. Based on the example given by Walsh (2015), writing activities can be adjusted to the four stages of the SAMR model in various ways: (1)Substitution level, writing handwriting on paper, students typing it on a mobile device using a note-taking application or digital tools such as Google Drive, Microsoft Office Online, Evernote, or Etherpad. (2) Augmentation level, when they write text on their mobile devices, students can highlight words, check spelling, and adjust the font format and style. They can also use voice toteks to convert spoken languages into written languages. (3) Modification levels, Students can enrich text by adding images, sounds, animations, and videos. They can also write text collaboratively using several online tools mentioned at the previous level, and receive teacher feedback through comments and explanations in the document. The best online writing application for collaboration to list tools for collaborative writing like google docs, microsoft word online, drop box paper, etherpad, quip, hackpad. (4) Redefinition level, students post their written production to their class blogs and share social networks like Twitter or Facebook. Hashtag on Twitter makes it easy for teachers and students to search for tweets about specific topics.

An interesting way to distribute and share written works is to use a QR code. A QR. Codes can be read using smartphones and tablets, and they are directly connected to articles, websites, videos and more in seconds.

From the four levels of SAMR model implementation, the substitution level changes a few traditional tools and activities in learning. At the next level, which is augmentation, technology still replaces traditional methods as the level of substitution; however, this also makes learning more efficient. After augmentation, the level of modification modifies the most significant method to open up new opportunities not found in traditional ways. Finally, in the last step, the level of redefinition, transformative experiences occur when learning itself becomes better.

This is a step that gives great opportunities for teachers and students to redefine their education systems according to educational needs in original digital. The SAMR model actually reminds us of Bloom's taxonomy (Krathwohl, 2010) a model often used in cognitive learning. SAMR has actually been applied in higher education to motivate students. However, SAMR is also good to apply in school. In the study, SAMR's main 
advantage was increasing motivation, interaction and collaboration.

\section{Conclusion}

The SAMR learning model has been shown to be effectively applied by teachers in integrating ICT (Information and Technology Technology) in learning. In this model, there are four levels that can integrate ICT in learning including substitution, augmentation, modification, and redefinition. This model uses hierarchies to describe cognitive levels. This model can also be parallel with Bloom's taxonomy model because both have the same level

\section{References}

Anderson, D.R. Krathwohl, P.W. Alrasian, K.A Cruskshank, R.E. Mayer, P.R. Pintrich, J.Reths, J., and M.C. Witrock. (2001). A Taxonomy Learning, Teaching, and Assesing: A revision of Bloom's Taxonomy of Educational Objevtives. New York : Pearson, Allyn \& Bacor.

Bloom, B.S., Engelhart, M.D, , Furst, E.J. Hill, W.H.\& Krathwohl D.S. (1956). Taxonomy of Educational Objectives, Handbook I: The cognitive Domain. New York: Longman, Green and Co Ltd.

Krathwohl, D.R. (2010). A Revision of Bloom's Taxonomy. Theory Pract., vol. 41, no. 4, pp. 212-218

Mueller, J.,Wood, E., De Pasquale, D.\& Archer,K. (2013).Students learning with mobile technologies in and out of the classroom. In Education in a Technological World: Communicating Current and Emerging Research and Technological Efforts. pp.5.

Puentedura,R.R.(2013).Hipasus.Retrievedfrom http://www.hippasus.com/rrpweblog/archives/2013/03/28/SAMRandTPCK_AnInt roduction.pdf

Walsh, K. (2015). 8 examples of transforming lessons through the SAMR cycle. Retrieved from http://www.emergingedtech.com/2015/04/examples-oftransforming-lessonsthrough-samr/ 